\title{
Physical Fitness Levels in Korean Adolescents: The National Fitness Award Project
}

\author{
Seunghee Lee, Byoung-Goo Ko, Saejong Park ${ }^{*}$ \\ Department of Sports Science, Korea Institute of Sports Science, Seoul, Korea
}

Background: Although physical fitness in adolescents has been widely studied, there is the lack of information regarding developmental patterns of various youth fitness components. The $L M S$ ( $L=$ skewness, $M=$ median curve, and $S$ = coefficient of variation) statistical method has been utilized to develop growth percentiles for height and weight as well as for fitness in the US and Europe countries. The purpose of this study was to develop age- and sex-specific smoothed percentile curves for fitness using the LMS method in Korean adolescents aged 13-18 years.

Methods: A sample of 14,794 adolescents (7,688 boys and 7,106 girls) who participated in the National Fitness Award Project in 2013 and 2014 was analyzed. The components were cardiorespiratory fitness (20-m PACER), muscle strength (handgrip strength), muscle endurance (partial curl-up, 30-s endurance jump), and flexibility (sit and reach). Age- and sex-specific smoothed percentile curves were calculated for fitness using the LMS method. Results: Age- and sex-specific smoothed percentile curves (5th, 10th, 25th, 50th, 75th, 90th, and 95th) were presented for each fitness component. Except for flexibility, fitness levels were higher in boys than in girls. In general, performance in fitness components, except for partial curl-ups, increased with age in boys. However, in girls, performance in fitness components, except for partial curl-ups, slightly increased or remained stable.

Conclusion: This study presented age- and sex-specific fitness percentile curves for Korean adolescents aged 1318 years. This material might be useful in understanding and evaluating the fitness status of Korean adolescents.

Key words: Adolescence, Physical fitness, Reference, Percentiles

\author{
Received June 27, 2016 \\ Reviewed July 4, 2016 \\ Accepted July 15, 2016 \\ *Corresponding author \\ Saejong Park \\ (iD) \\ http://orcid.org/0000-0001-7229-5790 \\ Department of Sports Science, Korea \\ Institute of Sports Science, \\ 727 Hwarang-ro, Nowon-gu, \\ Seoul 01794, Korea \\ Tel: +82-2-970-9562 \\ Fax: +82-2-970-9502 \\ E-mail: saejpark@sports.re.kr
}

\section{INTRODUCTION}

Health-related physical fitness in youth is known to affects health-related outcomes in adolescents as well as in adulthood. ${ }^{1,2}$ Physical fitness in youth is associated with musculoskeletal health and risk factors of cardiovascular disease ${ }^{3,4}$ Physical fitness has also positive effects on mental health, including depression and anxiety, as well as on academic performance in adolescence. ${ }^{3}$ Despite the significance of physical fitness in adolescence, most of Korean adolescents trend toward deteriorating physical fitness and increasing obesity rate. ${ }^{5}$ Korean adolescents represent declines of physical fitness levels as they advance grade levels, from elementary to middle and high school ${ }^{6}$, thus calling for strategies to improve physical fitness in adolescents. In the US, there is a nationwide physical fitness promotion program for youth, so called the FITNESSGRAM ${ }^{\circledR}$. In the FITNESSGRAM $^{\circledR}$, physical fitness percentiles were developed to manage youth physical fitness. ${ }^{7}$

A norm-referenced evaluation that provides the relative position of an individual's physical fitness level within a group is one of the most common ways to assess physical fitness. ${ }^{8}$ However, most of Korean youth fitness studies has been expensively reviewed in relation to the obesity. ${ }^{9-11}$ There were several studies on secular fitness trends for adolescents. ${ }^{5,12,13}$ In 2009 youth fitness criteria was set for the Physical Activity Promotion System (PAPS), but has some 
limitations such as selection bias in sampling and statistical modeling of growth status. ${ }^{14}$ Thus, norm-referenced fitness evaluations are needed with a large nationally representative sample in order to develop physical fitness reference for Korean adolescents which reflects growth. ${ }^{8}$

LMS $(\mathrm{L}$ curve $=$ skewness, $\mathrm{M}$ curve $=$ median, and $\mathrm{S}$ curve $=$ coefficient of variation) method has recently been used to identify reference values that affect growth status in adolescence (right skewed distribution). ${ }^{7,15,16}$ The method has also been used in the development of growth charts in the US and UK to present physical fitness percentile curves by age and $\operatorname{sex}^{17,18}$ and in the development of WHO growth charts in 2006. ${ }^{19}$

The LMS method was used to smooth a large data set that does not follow a normal distribution, calculating accurate z-scores by age and sex in order to present the data in standardized percentile curves. This method has also been used for assessing height and weight after independently developing growth charts for Korean children and adolescents in $2007 .{ }^{20}$ However, the LMS method has never been applied to physical fitness percentiles for Korean adolescents. Thus, the purpose of this study was to develop age- and sexspecific physical fitness smoothed percentiles curves for Korean adolescents (13-18 years of age) using the LMS method. The findings of this study, which reflect recent research trends on physical fitness evaluation, might be useful in understanding of the development of physical fitness in Korean adolescents.

\section{METHODS}

\section{Study participants}

This study used the raw data of preliminary and main measurements from the National Fitness Award Project (2013 and 2014) for adolescents aged $13-18$ years $(n=14,829)$. The preliminary measurements comprise raw data for youth physical fitness based on research as a part of the National Fitness Award Project, which was collected from a random sample of adolescents (by grade level) over 10 regions nationwide. The main data comprise measurements for adolescents who voluntarily participated in the National Fitness Award Project through the national fitness center in each region. We combined the 2 datasets for analysis in this study. Outliers $(n=35)$ were excluded in the study. As a result, physical fitness measurements from a total of 14,794 adolescents (7,688 males and 7,106 females) were included in the final analysis. The general characteristics of the participants are shown in Table 1.

\section{Study methods}

The components suggested in the National Fitness Award Project (i.e., body composition, aerobic capacity, muscular strength, muscular endurance, flexibility) were set as the parameters for physical fitness. The national physical fitness test items showed a high consistency, with reliability ranging from $0.87-0.99 .{ }^{21}$ All items were measured by a certified, professional health and fitness instructors.

Table 1. Physical characteristics of the participants

\begin{tabular}{|c|c|c|c|c|c|c|}
\hline & & \multicolumn{2}{|c|}{ Boys } & \multicolumn{2}{|c|}{ Girls } & \multirow{2}{*}{$P$} \\
\hline & & $\mathrm{N}$ & $\mathrm{M} \pm \mathrm{SD}$ & $\mathrm{N}$ & $\mathrm{M} \pm \mathrm{SD}$ & \\
\hline Age (year) & & 7,688 & $15.4 \pm 1.6$ & 7,106 & $15.1 \pm 1.6$ & $<0.001$ \\
\hline \multirow[t]{4}{*}{ Body composition } & Height (cm) & 7,688 & $169.5 \pm 7.8$ & 7,104 & $159.8 \pm 5.9$ & $<0.001$ \\
\hline & Weight (kg) & 7,688 & $63.1 \pm 13.9$ & 7,104 & $54.4 \pm 9.8$ & $<0.001$ \\
\hline & Body mass index $\left(\mathrm{kg} / \mathrm{m}^{2}\right)$ & 7,688 & $21.9 \pm 4.1$ & 7,106 & $21.3 \pm 3.4$ & $<0.001$ \\
\hline & Percent body fat (\%) & 7,625 & $18.1 \pm 8.4$ & 7,088 & $27.6 \pm 7.9$ & $<0.001$ \\
\hline \multirow[t]{2}{*}{ Aerobic capacity } & 20-m PACER (reps) & 7,664 & $46.9 \pm 21.7$ & 7,088 & $26.2 \pm 13.9$ & $<0.001$ \\
\hline & Estimated $\mathrm{VO}_{2} \max \left(\mathrm{mL} \cdot \mathrm{kg}^{-1} \cdot \mathrm{min}^{-1}\right)$ & 7,662 & $49.0 \pm 5.8$ & 7,085 & $39.0 \pm 4.8$ & $<0.001$ \\
\hline Muscular strength & Handgrip strength $(\mathrm{kg})$ & 7,677 & $33.5 \pm 0.1$ & 7,092 & $23.0 \pm 0.1$ & $<0.001$ \\
\hline \multirow[t]{2}{*}{ Muscular endurance } & Partial curl-up (reps) & 3,274 & $39.9 \pm 21.6$ & 3,595 & $30.9 \pm 22.1$ & $<0.001$ \\
\hline & 30-s endurance jump (reps) & 6,090 & $43.5 \pm 11.3$ & 5,808 & $28.4 \pm 10.8$ & $<0.001$ \\
\hline Flexibility & Sit and reach test $(\mathrm{cm})$ & 7,680 & $7.7 \pm 9.2$ & 7,103 & $13.5 \pm 9.4$ & $<0.001$ \\
\hline
\end{tabular}

Data are presented as mean $(\mathrm{m}) \pm$ standard deviation (SD).

PACER, progressive aerobic cardiovascular endurance run; $\mathrm{VO}_{2}$ max, maximal oxygen uptake. 


\section{Body composition measurement}

Body composition measurement comprised height $(\mathrm{cm})$, weight $(\mathrm{kg})$, body mass index (BMI), and percent body fat. Height was measured in units of $0.1 \mathrm{~cm}$ with a height scale and weight was recorded to the nearest $0.1 \mathrm{~kg}$. Percent body fat was measured using bioelectrical impedance analysis (BIA) with the Inbody v 320 (BioSpace, Seoul, Korea). All metals and accessories were removed for the measurements.

\section{Physical fitness measurement}

The physical fitness battery of The National Fitness Award Project is composed of aerobic capacity (Progressive Aerobic Cardiovascular Endurance Run: 20-m PACER), muscular strength (handgrip strength), muscular endurance (partial curl-up; 30-s endurance jump), and flexibility (sit and reach test). For the 20-m PACER, the maximum number of repetitions was recorded, and maximal oxygen uptake $\left(\mathrm{VO}_{2} \mathrm{max}\right)$ was calculated using a quadratic model based on the 20-m PACER measurement. ${ }^{22}$ Handgrip strength was individually measured twice for the left and right hands, and the highest value was recorded to the nearest $0.1 \mathrm{~kg}$. For the partial curlup, the maximum number of repetitions at the beep was recorded. Sit and reach was performed twice, and the highest measurement was recorded to the nearest $0.1 \mathrm{~cm}$. For the $30-\mathrm{s}$ endurance jump, the number of jumps performed in $30 \mathrm{~s}$ was recorded.

\section{Data analysis}

All data were presented as means and standard deviations. Statistical analyses were performed using SPSS v 18.0 (SPSS, Chicago, IL, USA) software, with the level of significance set to .05. Body composition and physical fitness were compared by sex using oneway analysis of variance (ANOVA).

Physical fitness was presented in age- and sex-specific percentiles (5th, 10th, 25th, 50th, 75th, 90th, and 95th) and curves using the LMS method. The LMS method provides a way of estimating percentile curves that are smoothed according to the maximum penalized likelihood. To compute physical fitness percentiles, we separated gender and used z-scores that were estimated by applying $\mathrm{L}$ curves by age (Box-Cox power to eliminate skewness), $\mathrm{M}$ curve (median), and cubic spline curve, a cubic function of the $S$ curve (coefficient of variation). LMS chartmaker software (Light V.2.54; by Tim Cole and Huiqi Pan) was used to compute L, M, and S values and percentiles.

\section{RESULTS}

Characteristics of the participants were presented as body composition and physical fitness parameters by sex (Table 1 ). Boys (15.4 \pm 1.6 years) were older than girls $(15.1 \pm 1.6$ years $)(P<$ 0.001). With regard to body composition, boys had greater height, weight, and BMI, but girls had higher percent body fat $(P<0.001)$. With regard to physical fitness variables, boys showed better performance in the following components: 20-m PACER, estimated $\mathrm{VO}_{2}$ max, handgrip strength, partial curl-up, and 30-s endurance jump $(P<0.001)$. On the other hand, girls showed better performance in sit and reach $(P<0.001)$.

The physical fitness percentiles by sex and age for each component were presented as curves in 7 intervals (5th, 10th, 25th, 50th, 75th, 90th, and 95th) (Fig. 1). In boys, overall physical fitness was either unchanged or declined at age 15-16 years. Whereas boys tended to show better 20-m PACER, handgrip strength, 30-s endurance jump, and sit and reach performance with advancing age, their partial curl-up performance declined with advancing age. In girls, overall physical fitness also was either unchanged or declined at age 15-16 years. Girls showed consistent 20-m PACER and 30-s endurance jump performance regardless of advancing age. Although their partial curl-up performance mildly deteriorated with advancing age, handgrip strength and sit and reach performance mildly improved.

We presented $L$ values, $M$ values, $S$ values, and percentiles for each physical fitness component by age and sex (Tables 2-6). The L, M, and $S$ values by age and sex could be plugged into an equation along with the actual physical fitness measurements to compute an individual's percentile (z-score). Conversely, physical fitness values that fall under a certain percentile could also be computed [equation zscore $\left.=\left[(\text { actual measurement } / \mathrm{M})^{\mathrm{L}}-1\right] /(\mathrm{L} \times \mathrm{S})\right]^{23}$

\section{DISCUSSION}

Physical fitness in youth affects health in adolescence as well as in adulthood. ${ }^{3}$ Physical fitness criteria for youth are extensively stud- 
Aerobic capacity

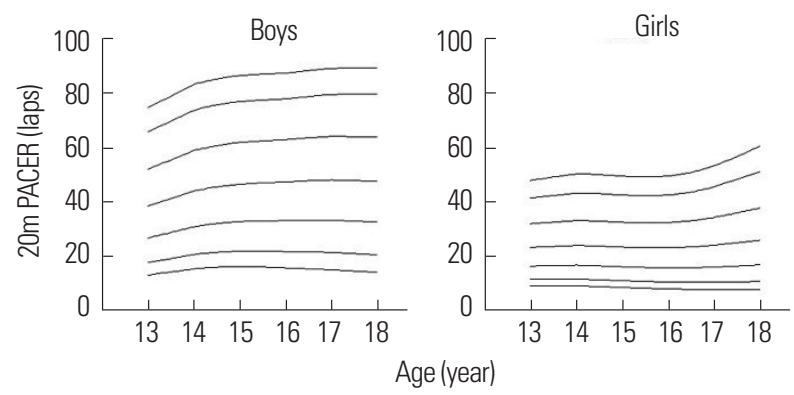

Muscular endurance

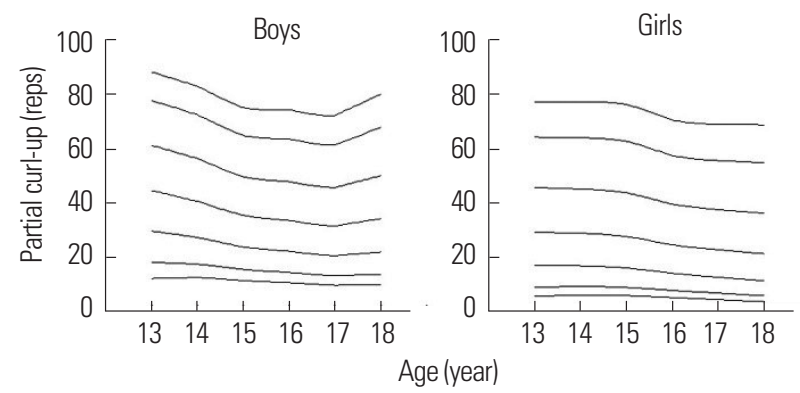

Flexibility

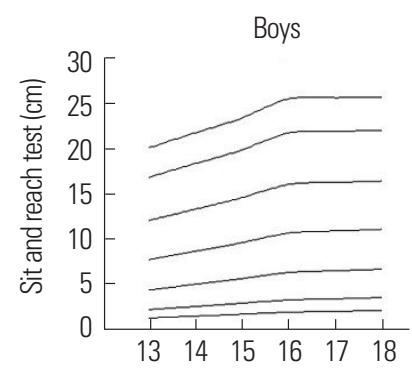

Girls

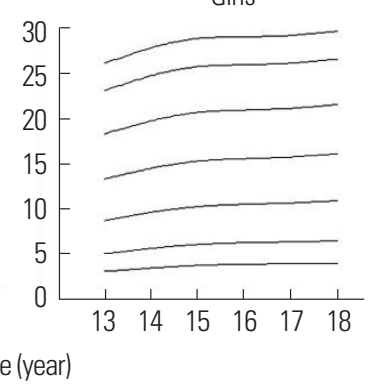

Muscular strength

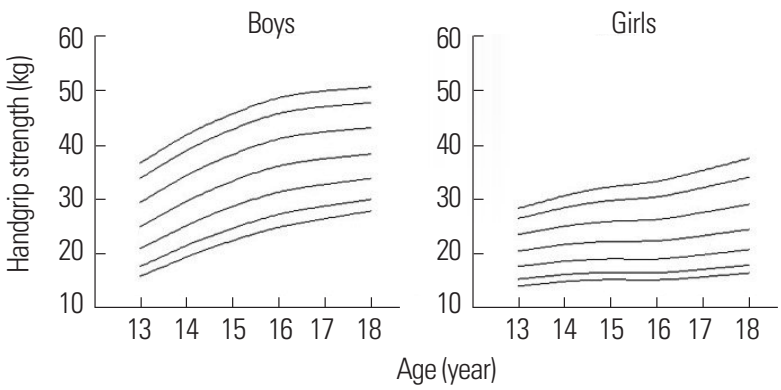

Muscular endurance
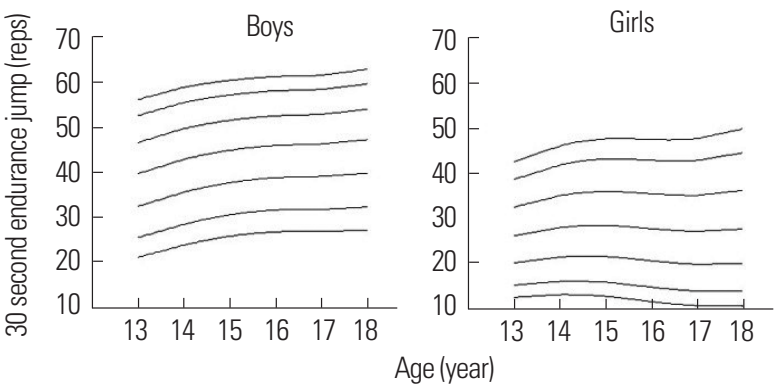

Figure 1. Smoothed (LMS method) centile curves of the 5th, 10th, 25th, 50th, 75th, 90th, and 95th for physical fitness tests. PACER, progressive aerobic cardiovascular endurance run.

Table 2. Age- and sex-specific LMS values and percentiles for 20-m PACER (reps)

\begin{tabular}{lcccccccccc}
\hline & $\mathrm{L}$ & $\mathrm{M}$ & $\mathrm{S}$ & 5 th & 10th & 25th & 50th & 75th & 90th & 95th \\
\hline Boys (year) & & & & & & & & & & \\
13 & 0.569 & 38.4 & 0.489 & 13.1 & 17.7 & 26.6 & 38.4 & 52.0 & 65.6 & 74.5 \\
14 & 0.607 & 43.9 & 0.472 & 15.4 & 20.7 & 30.8 & 43.9 & 58.7 & 73.5 & 82.9 \\
15 & 0.651 & 46.4 & 0.464 & 16.2 & 21.9 & 32.7 & 46.4 & 61.7 & 76.7 & 86.2 \\
16 & 0.704 & 47.2 & 0.467 & 15.6 & 21.7 & 33.1 & 47.2 & 62.7 & 77.7 & 87.2 \\
17 & 0.733 & 47.9 & 0.475 & 15.0 & 21.4 & 33.3 & 47.9 & 63.9 & 79.3 & 88.9 \\
18 & 0.737 & 47.5 & 0.488 & 14.1 & 20.5 & 32.6 & 47.5 & 63.8 & 79.4 & 89.2 \\
Girls (year) & & & & & & & & & \\
13 & 0.313 & 23.5 & 0.484 & 9.4 & 11.8 & 16.7 & 23.5 & 32.1 & 41.5 \\
14 & 0.301 & 24.2 & 0.498 & 9.5 & 11.9 & 17.0 & 24.2 & 33.3 & 43.4 & 57.9 \\
15 & 0.328 & 23.6 & 0.509 & 8.9 & 11.3 & 16.4 & 23.6 & 32.7 & 42.7 & 49.5 \\
16 & 0.360 & 23.4 & 0.524 & 8.3 & 10.8 & 16.0 & 23.4 & 32.6 & 42.7 & 49.6 \\
17 & 0.355 & 24.3 & 0.552 & 8.1 & 10.7 & 16.3 & 24.3 & 34.4 & 45.6 & 53.3 \\
18 & 0.316 & 26.1 & 0.588 & 8.2 & 11.0 & 17.1 & 26.1 & 37.9 & 51.3 & 60.7 \\
\hline
\end{tabular}

L, skewness; M, median; S, standard deviation; PACER, progressive aerobic cardiovascular endurance run. 
Table 3. Age- and sex-specific LMS values and percentiles for handgrip strength (kg)

\begin{tabular}{|c|c|c|c|c|c|c|c|c|c|c|}
\hline & L & $\mathrm{M}$ & S & 5th & 10th & 25th & 50th & 75th & 90th & 95th \\
\hline \multicolumn{11}{|c|}{ Boys (year) } \\
\hline 13 & 0.393 & 24.8 & 0.254 & 15.7 & 17.5 & 20.8 & 24.8 & 29.3 & 33.7 & 36.5 \\
\hline 14 & 0.545 & 29.5 & 0.232 & 19.2 & 21.3 & 25.0 & 29.5 & 34.3 & 38.8 & 41.7 \\
\hline 15 & 0.651 & 33.2 & 0.214 & 22.2 & 24.5 & 28.5 & 33.2 & 38.1 & 42.7 & 45.6 \\
\hline 16 & 0.666 & 36.0 & 0.202 & 24.7 & 27.1 & 31.2 & 36.0 & 41.0 & 45.7 & 48.6 \\
\hline 17 & 0.616 & 37.3 & 0.192 & 26.3 & 28.6 & 32.6 & 37.3 & 42.3 & 47.0 & 49.8 \\
\hline 18 & 0.477 & 38.2 & 0.182 & 27.7 & 29.8 & 33.7 & 38.2 & 43.0 & 47.6 & 50.5 \\
\hline \multicolumn{11}{|c|}{ Girls (year) } \\
\hline 13 & 0.447 & 20.4 & 0.213 & 14.0 & 15.3 & 17.6 & 20.4 & 23.5 & 26.4 & 28.3 \\
\hline 14 & 0.225 & 21.6 & 0.221 & 14.8 & 16.1 & 18.6 & 21.6 & 25.0 & 28.4 & 30.6 \\
\hline 15 & 0.056 & 22.2 & 0.230 & 15.1 & 16.5 & 19.0 & 22.2 & 25.9 & 29.7 & 32.2 \\
\hline 16 & -0.056 & 22.3 & 0.240 & 15.1 & 16.4 & 19.0 & 22.3 & 26.2 & 30.4 & 33.2 \\
\hline 17 & -0.134 & 23.2 & 0.246 & 15.7 & 17.1 & 19.7 & 23.2 & 27.5 & 32.1 & 35.3 \\
\hline 18 & -0.165 & 24.4 & 0.251 & 16.4 & 17.8 & 20.7 & 24.4 & 29.0 & 34.0 & 37.5 \\
\hline
\end{tabular}

L, skewness; M, median; S, standard deviation.

Table 4. Age- and sex-specific LMS values and percentiles for partial curl-up (reps)

\begin{tabular}{lcccccccccc}
\hline & $\mathrm{L}$ & $\mathrm{M}$ & $\mathrm{S}$ & 5 th & 10th & 25th & 50th & 75th & 90th & 95th \\
\hline Boys (year) & & & & & & & & & & \\
13 & 0.672 & 44.4 & 0.529 & 12.0 & 18.0 & 29.5 & 44.4 & 61.2 & 77.7 & 88.1 \\
14 & 0.541 & 40.5 & 0.533 & 12.4 & 17.3 & 27.1 & 40.5 & 56.2 & 72.3 & 82.9 \\
15 & 0.441 & 35.2 & 0.545 & 11.2 & 15.3 & 23.6 & 35.2 & 49.6 & 64.8 & 75.0 \\
16 & 0.382 & 33.4 & 0.569 & 10.5 & 14.2 & 22.1 & 33.4 & 47.8 & 63.5 & 74.3 \\
17 & 0.362 & 31.4 & 0.590 & 9.5 & 13.0 & 20.4 & 31.4 & 45.6 & 61.3 & 72.2 \\
18 & 0.365 & 34.1 & 0.612 & 9.7 & 13.5 & 21.8 & 34.1 & 50.0 & 67.9 & 80.3 \\
Girls (year) & & & & & & & & & \\
13 & 0.421 & 29.1 & 0.733 & 5.4 & 8.8 & 16.7 & 29.1 & 45.6 & 64.3 & 77.2 \\
14 & 0.375 & 28.7 & 0.730 & 5.8 & 9.1 & 16.6 & 28.7 & 45.1 & 64.0 & 77.4 \\
15 & 0.343 & 27.5 & 0.743 & 5.6 & 8.7 & 15.9 & 27.5 & 43.7 & 62.7 & 76.3 \\
16 & 0.319 & 24.5 & 0.765 & 4.9 & 7.6 & 13.9 & 24.5 & 39.4 & 57.4 & 70.5 \\
17 & 0.301 & 22.6 & 0.805 & 4.2 & 6.6 & 12.5 & 22.6 & 37.4 & 55.6 & 69.0 \\
18 & 0.294 & 21.2 & 0.857 & 3.4 & 5.6 & 11.2 & 21.2 & 36.1 & 54.8 & 68.8 \\
\hline
\end{tabular}

L, skewness; M, median; S, standard deviation.

Table 5. Age- and sex-specific LMS values and percentiles for 30-s endurance jump (reps)

\begin{tabular}{lllllllllll}
\hline & $\mathrm{L}$ & $\mathrm{M}$ & $\mathrm{S}$ & 5 th & 10th & 25th & 50th & 75th & 90th & 95th \\
\hline Boys (year) & & & & & & & & & & \\
13 & 1.256 & 39.7 & 0.264 & 21.2 & 25.5 & 32.4 & 39.7 & 46.6 & 52.6 & 56.1 \\
14 & 1.415 & 42.9 & 0.243 & 23.8 & 28.4 & 35.6 & 42.9 & 49.7 & 55.5 & 58.9 \\
15 & 1.520 & 44.9 & 0.228 & 25.8 & 30.5 & 37.7 & 44.9 & 51.5 & 57.2 & 60.4 \\
16 & 1.577 & 46.0 & 0.221 & 26.8 & 31.6 & 38.8 & 46.0 & 52.5 & 58.1 & 61.3 \\
17 & 1.616 & 46.3 & 0.220 & 26.8 & 31.7 & 39.1 & 46.3 & 52.9 & 58.4 & 61.6 \\
18 & 1.635 & 47.2 & 0.221 & 27.2 & 32.3 & 39.8 & 47.2 & 54.0 & 59.6 & 62.9 \\
Girls (year) & & & & & & & & & \\
13 & 0.684 & 26.4 & 0.349 & 12.8 & 15.5 & 20.5 & 26.4 & 32.9 & 39.1 & 42.9 \\
14 & 0.674 & 28.3 & 0.358 & 13.4 & 16.3 & 21.7 & 28.3 & 35.4 & 42.2 & 46.5 \\
15 & 0.685 & 28.8 & 0.373 & 13.0 & 16.1 & 21.8 & 28.8 & 36.3 & 43.5 & 48.0 \\
16 & 0.702 & 28.0 & 0.395 & 11.8 & 15.0 & 20.9 & 28.0 & 35.8 & 43.2 & 47.9 \\
17 & 0.682 & 27.4 & 0.415 & 10.9 & 14.2 & 20.1 & 27.4 & 35.4 & 43.2 & 48.1 \\
18 & 0.628 & 28.0 & 0.431 & 11.0 & 14.2 & 20.3 & 28.0 & 36.5 & 44.9 & 50.2 \\
\hline
\end{tabular}

L, skewness; M, median; S, standard deviation. 
Table 6. Age- and sex-specific LMS values and percentiles for sit and reach test (cm)

\begin{tabular}{|c|c|c|c|c|c|c|c|c|c|c|}
\hline & L & M & S & 5th & 10th & 25th & 50th & 75th & 90th & 95th \\
\hline \multicolumn{11}{|c|}{ Boys (year) } \\
\hline 13 & 0.473 & 7.7 & 0.737 & 1.3 & 2.2 & 4.4 & 7.7 & 12.1 & 16.8 & 20.1 \\
\hline 14 & 0.504 & 8.7 & 0.712 & 1.5 & 2.6 & 5.0 & 8.7 & 13.3 & 18.3 & 21.7 \\
\hline 15 & 0.528 & 9.6 & 0.691 & 1.7 & 2.9 & 5.6 & 9.6 & 14.6 & 19.9 & 23.4 \\
\hline 16 & 0.546 & 10.7 & 0.678 & 1.9 & 3.3 & 6.3 & 10.7 & 16.1 & 21.7 & 25.5 \\
\hline 17 & 0.557 & 10.9 & 0.666 & 2.0 & 3.4 & 6.5 & 10.9 & 16.3 & 21.9 & 25.6 \\
\hline 18 & 0.568 & 11.1 & 0.653 & 2.1 & 3.6 & 6.7 & 11.1 & 16.4 & 22.0 & 25.6 \\
\hline \multicolumn{11}{|c|}{ Girls (year) } \\
\hline 13 & 0.762 & 13.3 & 0.536 & 3.1 & 5.0 & 8.7 & 13.3 & 18.3 & 23.1 & 26.1 \\
\hline 14 & 0.794 & 14.5 & 0.520 & 3.5 & 5.6 & 9.6 & 14.5 & 19.7 & 24.7 & 27.8 \\
\hline 15 & 0.822 & 15.3 & 0.507 & 3.7 & 6.0 & 10.2 & 15.3 & 20.6 & 25.7 & 28.8 \\
\hline 16 & 0.841 & 15.5 & 0.498 & 3.9 & 6.2 & 10.5 & 15.5 & 20.9 & 25.9 & 29.0 \\
\hline 17 & 0.854 & 15.7 & 0.494 & 3.9 & 6.3 & 10.6 & 15.7 & 21.1 & 26.1 & 29.1 \\
\hline 18 & 0.873 & 16.1 & 0.491 & 4.0 & 6.4 & 10.9 & 16.1 & 21.5 & 26.5 & 29.6 \\
\hline
\end{tabular}

L, skewness; M, median; S, standard deviation.

ied in the US and Europe for the management of declining physical fitness and increasing obesity rates in adolescence. ${ }^{7,15}$ However, a majority of Korean studies on youth physical fitness assessment focused on presenting yearly trends and criteria with reference to obesity. ${ }^{5,9-13}$ Furthermore, the PAPS modified in 2009 failed to consider the limitations of selection bias in sampling and growth status in evaluating adolescent physical fitness. ${ }^{14}$ To address such problems, the LMS method has been used in the US and Europe to present physical fitness percentile curves by age and $\operatorname{sex}^{7,15,16}$, but no such attempt has been made in Korea. This highlights the need to develop new physical fitness criteria in Korea that reflect adolescent growth, to remain current with recent research trends.

The present study utilized large-scale data for 14,792 boys and girls aged 13-18 years who participated in the 2013 and $2014 \mathrm{Na}$ tional Fitness Award Project. This was the first study in Korea to present physical fitness percentile curves by age and sex using the LMS method. According to our findings, boys showed better performance with advancing age in most of the physical fitness components, but girls showed no change or mild improvement in physical fitness with advancing age. On the other hand, boys and girls showed declining flexibility and muscular endurance (partial curlup), respectively, with advancing age.

\section{Aerobic capacity}

Boys showed better 20-m PACER performance than girls did.
Whereas boys showed increasing aerobic capacity with advancing age, with a plateau after age 16, girls showed consistent aerobic capacity as they aged. This is consistent with the general knowledge of growth and development of cardiorespiratory fitness by age in male and female adolescents. ${ }^{24}$ The difference in cardiorespiratory fitness by sex may reflect the increased muscle mass and oxygen delivery associated with increased male hormones (testosterone) in male adolescents following puberty. ${ }^{25}$ Based on the aerobic capacity criterion suggested by PAPS $^{26}$, only a small proportion of students were in the top grades (grades 1 and 2), while a larger proportion of students were in the lower grades (grades 4 and 5), among both boys and girls (boys > grade 2: 34.7\%, < grade 4: 42.5\%; girls > grade 2: $26.6 \%$, < grade $4: 46.9 \%)$. In other words, most boys and girls had low aerobic capacity, which was in line with the findings of a previous study that reported deterioration of physical fitness in adolescents in accordance with differences in generations. ${ }^{12}$

When we compared the aerobic capacity $\left(\mathrm{VO}_{2} \max \right)$ of Korean boys and girls with those of American counterparts ${ }^{7}$, Korean youth tended to have higher aerobic capacity (median, 50th percentile) by sex and age than those of American counterparts (Fig. 2). This also supports the findings of a prior Korean study on Korean and American adolescents aged 14 years (1.5-Mile run). ${ }^{27}$ Although direct comparison is limited owing to the differences in ages of the subjects and selected aerobic capacity components (20-m PACER vs 1.5-Mile run), Korean adolescents are thought to have higher aero- 


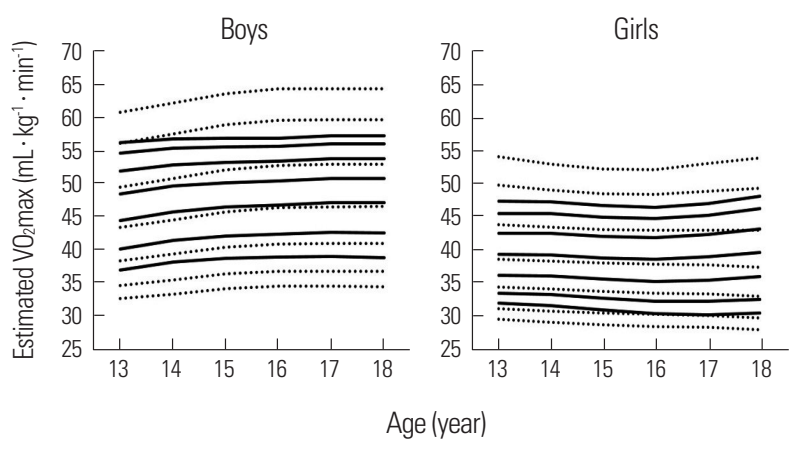

Figure 2. Comparative smoothed centile curves of the 5th, 10th, 25th, 50th, 75th, 90th, and 95th for the estimated $\mathrm{VO}_{2} \max$ between Korean (solid lines) and US (dotted lines).

bic capacity than American adolescents. ${ }^{27}$ In addition, adolescents below the 75th percentile had higher aerobic capacity than that of their American counterparts, but adolescents above the 75th percentile had lower aerobic capacity than that of their American counterparts. Such results reflect previous reports of declining cardiorespiratory fitness with increasing obesity ${ }^{28,29}$, and allude to the fact that differences in obesity between Korean and American adolescents may play a role in the differences in physical fitness between the groups. Both boys and girls in this study had lower BMI than that of American adolescents, which is presumed to have contributed to the differences in their cardiorespiratory fitness (boys $21.9 \pm 4.1$ vs $22.7 \pm 0.2 \mathrm{~kg} / \mathrm{m}^{2}$, girls $21.3 \pm 3.4$ vs $23.0 \pm 0.2 \mathrm{~kg} / \mathrm{m}^{2}$ ). Furthermore, the differences in the cardiorespiratory fitness of Korean and American adolescents may also be related to the $\mathrm{VO}_{2} \mathrm{max}$ equation used in this study. Whereas American studies estimate $\mathrm{VO}_{2}$ max based on a submaximal exercise test, we used the maximal values of the 20-m PACER, which is the gold standard. $\mathrm{VO}_{2} \mathrm{max}$ is intimately related to cardiac function, and is the most widely used standard for measuring cardiorespiratory fitness. ${ }^{30}$ Despite the limitations in direct comparison of results due to differences in estimation equations, the comparison of $\mathrm{VO}_{2} \max$ is meaningful in identifying the trends in cardiorespiratory fitness by age and sex.

\section{Muscular strength}

Handgrip strength, a component of muscular strength, was greater in boys than in girls. Muscular strength increased with advancing age and plateaued after the age of 16 in boys, while it remained largely unchanged in girls, even with advancing age, similar

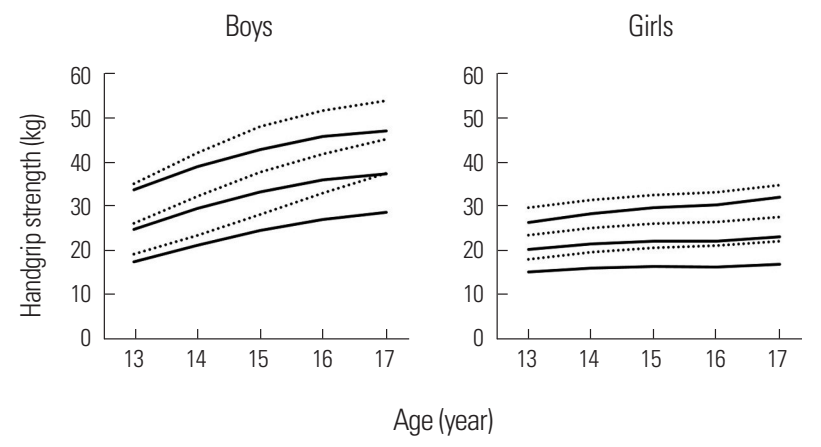

Figure 3. Comparative smoothed centile curves of the 10th, 50th, 90th for the handgrip strength test between Korean (solid lines) and European (dotted lines).

to previous findings. ${ }^{5}$ Such differences in muscular strength between boys and girls are a result of the differences in sex hormones that are produced after puberty. Whereas boys have a rapid increase in lean body mass, girls only have a mild increase of lean body mass due to increased body fat mass. ${ }^{25}$ Based on the PAPS handgrip evaluation criterion ${ }^{26}$, only a small proportion of students were in the top grades (grades 1 and 2) while a larger proportion of students were in the lower grades (grades 4 and 5) in both boys and girls (boys > grade 2: 16.2\%, < grade 4: 48.0\%; girls > grade 2: $18.1 \%$, < grade $4: 41.8 \%)$. In other words, most boys and girls had low muscular strength.

When the muscular strength (handgrip strength) of adolescents in this study was compared to that of European counterparts ${ }^{15}$, both boys and girls had lower values, but showed similar age-specific curves (Fig. 3). In boys, handgrip strength in 13-year-olds was similar to that of European boys, but the rate of increase in muscular strength after the age of 14 was smaller than that of European boys. This is thought to be influenced by the fact that Korean and European adolescents have similar BMI (boys $21.9 \pm 4.1$ vs $21.6 \pm 4.0$ $\mathrm{kg} / \mathrm{m}^{2}$, girls $21.3 \pm 3.4 \mathrm{vs} 21.4 \pm 3.5 \mathrm{~kg} / \mathrm{m}^{2}$ ) but show differences in lean body mass, which is related to handgrip strength. ${ }^{28}$ In addition, a previous Korean study revealed that only $20.1 \%$ of all male and female adolescents perform muscle strengthening exercise at least 3 times a week, indicating the inadequacy of muscle strength training in Korean adolescents. ${ }^{31}$ As muscle strength is another independent risk factor for cardiovascular disease in addition to cardiorespiratory fitness $^{3}$, Korean adolescents should be encouraged to perform regular muscle strengthening exercise. 


\section{Muscular endurance}

There was a decreasing trend in partial curl-up performance in both boys and girls with advancing age, which was similar to the results of a previous Korean study. ${ }^{5}$ Based on the PAPS partial curlup criterion ${ }^{26}$, only a small proportion of boys were in the upper grades (grades 1 and 2), with a higher proportion in the lower grades (grades 4 and 5), while the opposite was true for girls (boys > grade 2: 16.9\%, < grade 4: 47.4\%; girls > grade 2: $32.4 \%$, $<$ grade $4: 28.1 \%$ ). In other words, boys had lower muscle endurance while girls had higher muscle endurance than boys.

When compared with European adolescents ${ }^{16}$, both boys and girls in this study had inferior partial curl-up performance. The trends were also quite different, as European adolescents showed a trend of increasing partial curl-up performance with advancing age. With regard to the 30-s endurance jump, boys showed better performance with advancing age while girls tended to show consistent performance, even with advancing age, which was similar to the trend for bent-arm hang performance in European adolescents. ${ }^{16}$

The National Fitness Award Project suggests 2 muscular endurance components as essential for adolescents: partial curl-up to test endurance of abdominal muscles, and endurance jump to test endurance of lower limb muscles. In contrast to the anticipation that adolescent muscle endurance would increase with advancing age, there were different trends for different areas of muscles, even for the same muscle endurance components. A previous study showed that underweight and normal-weight adolescents had higher muscular endurance than did obese adolescents, suggesting an association between body weight and relative muscle strength. ${ }^{16}$ In the future, studies should examine the associations among various muscle endurance components and other factors, including body composition.

\section{Flexibility}

Girls showed better sit and reach performance (flexibility) than did boys. Flexibility increased with advancing age in both sexes, with only mild increases after the ages of 16 for boys and 15 for girls, which was similar to the findings of a previous study. ${ }^{5}$ This trend was similar to that for growth and development of flexibility in adolescents by $\operatorname{age}^{24}$, and the sex difference in the development of flexibility is presumed to be a result of greater growth of sitting height (trunk length) in girls after the age of $11 .^{32}$ Based on the
PAPS criterion for sit and reach ${ }^{26}$, a high proportion of the students was in the top grades, but a smaller proportion was in the lower grades in both sexes (boys > grade 2: 48.8\%, < grade 4: 30.0\%; girls > grade $2: 64.3 \%$, < grade $4: 25.4 \%)$. In other words, most boys and girls showed relatively good flexibility.

A limitation of this study, despite the use of large-scale data, is the use of reference values based on a cross-sectional analysis. A longitudinal study, which continuously follows-up on growth and maturation over time, is required to achieve complete understanding of the development of physical fitness in adolescence. However, the representativeness of our sample is largely unchanged from that shown by the 2007 Growth Charts for Korean Children and Adolescents suggested by the Centers for Disease Prevention and Control (z-scores of sex- and age-specific height, weight, BMI 0.01$0.20 \pm 0.9-1.2) .^{20}$

This study presented health-related physical fitness percentiles based on large-scale data for adolescents who participated in the National Fitness Award Project. The use of the LMS method enabled us to factor adolescent growth into our analysis and compare some physical fitness components with those of foreign adolescents, which may also be useful for understanding the level of physical fitness of Korean adolescents. However, prospective cohort studies are required to strengthen the features of physical fitness criteria, and continuous studies and management of measurement data are also important.

\section{CONFLICTS OF INTEREST}

The authors declare that they have no competing interests.

\section{ACKNOWLEDGMENTS}

This study was supported by research grants from Korea Sports Promotion Foundation. The authors thank the participants for their time and effort during this study.

\section{REFERENCES}

1. Zaichkowsky LD, Larson GA. Physical motor, and fitness development in children and adolescents. J Educ 1995;177:55- 
79.

2. Malina RM. Physical activity and fitness: pathways from childhood to adulthood. Am J Hum Biol 2001;13:162-72.

3. Ortega FB, Ruiz JR, Castillo MJ, Sjöström M. Physical fitness in childhood and adolescence: a powerful marker of health. Int J Obes (Lond) 2008;32:1-11.

4. McKenzie TL. Promoting physical activity in youth: focus on middle school environments. Quest 2001;53:326-34.

5. Chae JS, Shin JY. Trend analysis of physique and physical fitness according to the time of children and youth in Korea. The Korean Journal of Measurement and Evaluation in Physical Education and Sport Science 2015;17:23-38.

6. Ministry of Education. The 2014 school health examination sample survey findings. [serial online] 2015; Available from: URL: http://www.moe.go.kr/boardCnts/view.do?boardID=3 $48 \&$ lev $=0 \&$ status $Y \mathrm{~N}=\mathrm{W} \& \mathrm{~s}=\mathrm{moe} \& \mathrm{~m}=040103 \&$ opType $=\mathrm{N} \&$ boardSeq $=60946$

7. Eisenmann JC, Laurson KR, Welk GJ. Aerobic fitness percentiles for U.S. adolescents. Am J Prev Med 2011;41(Suppl 2): 106-10.

8. Kim JT. Kinemetrics. Seoul: Rainbowbooks; 2014. p. 105-20.

9. Ko BG, Song HS, Park SJ, Jung JU, Lee GB, Lee SN, et al. The development of Korean youth aerobic-capacity standards using receiver operating characteristic curves. The Korean Journal of Measurement and Evaluation in Physical Education and Sport Science 2015;17:69-82.

10. Kim MY. Establishing a BMI cut-off for overweight and obesity in adolescents using receiver operating characteristic curve. The Korean Journal of Physical Education 2008;47:761-9.

11. Kim YW, Oh SH. Usefulness of cardiorespiratory fitness cutoff value for predicting adolescent obesity using an indirect measurement of maximal oxygen uptake. Journal of Sport and Leisure Studies 2014;56:945-58.

12. Kim HK, Lim HJ, Park HJ, Park JE, Ahn HY, Kim M. Secular trends and gender differences in Korean adolescents' physical fitness. Journal of Physical Growth and Motor Development 2002;10:9-21.

13. Song JK, Kang HJ, Jung HC, Kim HB, Son WI. Tracking of skeletal maturity, body composition, and health-related fitness during adolescence. The Korean Journal of Growth and De- velopment 2011;19:261-70.

14. Kim MY, Kim YW, Cho YI, Oh SH. Setting criterion for the fitness test in physical activity promotion system. The Korean Journal of Measurement and Evaluation in Physical Education and Sport Science 2008;10:59-68.

15. Ortega FB, Artero EG, Ruiz JR, España-Romero V, JiménezPavón D, Vicente-Rodriguez G, et al. Physical fitness levels among European adolescents: the HELENA study. Br J Sports Med 2011;45:20-9.

16. Castro-Piñero J, González-Montesinos JL, Mora J, Keating XD, Girela-Rejón MJ, Sjöström M, et al. Percentile values for muscular strength field tests in children aged 6 to 17 years: influence of weight status. J Strength Cond Res 2009;23:2295310.

17. Wright CM, Booth IW, Buckler JM, Cameron N, Cole TJ, Healy MJ, et al. Growth reference charts for use in the United Kingdom. Arch Dis Child 2002;86:11-4.

18. Kuczmarski RJ, Ogden CL, Guo SS, Grummer-Strawn LM, Flegal KM, Mei Z, et al. 2000 CDC growth charts for the United States: methods and development. Vital Health Stat 11 2002;246:1-190.

19. WHO Multicentre Growth Reference Study Group. WHO Child Growth Standards: Length/height-for-age, weight-forage, weight-for-length, weight-for-height and body mass indexfor-age: Methods and development. Geneva: World Health Organization; 2006. p. 312.

20. Moon JS, Lee SY, Nam CM, Choi JM, Choe BK, Seo JW, et al. 2007 Korean national growth charts: review of developmental process and an outlook. Korean J Pediatr 2008;51:1-25.

21. Ko BG, Kim YR, Sung BJ, Chung DS, Youn SW, Lee JK, et al. Development of criteria for Korea youth fitness award. Korean J Sport Sci 2005;16:44-63.

22. Mahar MT, Guerieri AM, Hanna MS, Kemble CD. Estimation of aerobic fitness from 20-m multistage shuttle run test performance. Am J Prev Med 2011;41(Suppl 2):117-23.

23. Cole TJ. The LMS method for constructing normalized growth standards. Eur J Clin Nutr 1990;44:45-60.

24. Seefeldt V. Physical Activity \& Well-being. In: Haubenstricker J, Seefeldt V, editors. Acquisition of motor skills during childhood. US: American alliance for health, physical education, 
recreation and dance; 1986. p. 41-102.

25. Malina RM, Bouchard C, Bar-Or O. Growth, maturation, and physical activity. 2nd ed. US: Human Kinetics; 2004.

26. Ministry of Education. Physical activity promotion system evaluation (PAPS) manual. 2009.

27. Park KY. Analysis of physical characteristic and physical fitness of Korean and American young ages. Journal of the Humanities 1992;14:105-16.

28. Mota J, Guerra S, Leandro C, Pinto A, Ribeiro JC, Duarte JA. Association of maturation, sex, and body fat in cardiorespiratory fitness. Am J Hum Biol 2002;14:707-12.
29. Park MJ, Suh SH. Evaluation of physical fitness in terms of levels of obesity among middle and high school students in Seoul. Korean J Obes 2009; 18:65-71.

30. American College of Sports Medicine. ACSM's guidelines for exercise testing and prescription. 9th ed. US: Lippincott Williams \& Wilkins; 2013.

31. Korea Center for Disease Control and Prevention. The ninth Korea youth risk behavior web-based survey. 2013.

32. Roche AF, Malina RM. Manual of physical status and performance in childhood: Volume 1B: physical status. Springer Science \& Business Media; 2012. 